\title{
Effect of an oral gold compound, auranofin, on non-specific bronchial hyperresponsiveness in mild asthma
}

\author{
Masaaki Honma, Gen Tamura, Kunio Shirato, Tamotsu Takishima
}

\begin{abstract}
Background - A recent double blind clinical trial in Japan has shown that auranofin (6 mg/day) is a useful treatment for patients with moderate to severe asthma. To investigate the mechanism of action of auranofin the bronchial responsiveness to inhaled methacholine has been studied in well controlled asthmatic subjects.

Methods - Nineteen adult asymptomatic asthmatic subjects received auranofin ( $3 \mathrm{mg}$ orally twice a day) or inactive placebo in random order for 12 weeks in a double blind fashion. Bronchial responsiveness to inhaled methacholine and pulmonary function tests were measured at the same time on different days before, and six and 12 weeks after, each treatment.
\end{abstract}

Results - Non-specific bronchial hyperresponsiveness 12 weeks after treatment with auranofin was decreased compared with that before treatment with auranofin and 12 weeks after treatment with inactive placebo, although the treatment did not improve pulmonary function tests.

Conclusions - Non-specific bronchial hyperresponsiveness 12 weeks after treatment with auranofin is decreased in a group of mild asymptomatic asthmatic patients with normal lung function.

(Thorax 1994;49:649-651)

At present few gold compounds are approved for treatment of bronchial asthma because they can have severe adverse effects and, moreover, other effective drugs are available. However, gold compounds have been used for the treatment of patients with severe asthma since the 1950s and can improve non-specific bronchial hyperresponsiveness in patients with steroiddependent asthma after long term therapy. ${ }^{1}$

Auranofin is an oral gold compound used for the treatment of rheumatoid arthritis ${ }^{2}$ and has fewer adverse effects than other gold compounds. ${ }^{3}$ It has recently been reported in an open trial that auranofin was of benefit in the treatment of patients with steroid-dependent asthma. ${ }^{4}$ In addition a double blind, multicentre study in Japan showed that treatment with auranofin for more than 12 weeks was beneficial for moderate to severe asthmatics. In the present study we have investigated the effect of auranofin on non-specific bronchial hyperresponsiveness in asymptomatic asth- matic patients in a double blind, placebo controlled fashion.

\section{Methods}

PATIENTS

Twenty five asymptomatic outpatients with bronchial asthma were recruited from our asthma clinic. Patients who had received systemic steroid treatment were excluded from the study. All other routinely used agents were continued for 12 weeks before and during the period of the study. Of 15 patients receiving beclomethasone dipropionate 13 had taken it for more than one year and two for more than six months. None had experienced an exacerbation of asthma or respiratory tract infection for 12 weeks before the study. The study was approved by the ethics committee of the Tohoku University School of Medicine and all patients gave written informed consent.

\section{STUDY DESIGN}

Auranofin or placebo, in $3 \mathrm{mg}$ tablet form, was administered orally twice a day for 12 weeks in a double blind fashion. Blood sampling and measurements of bronchial responsiveness to methacholine and pulmonary function tests were carried out at the same time on different days before, and six and 12 weeks after, each treatment. All subjects were required to record clinical symptoms and concomitant medication during the study period.

METHACHOLINE CHALLENGE AND PULMONARY FUNCTION TESTS

Bronchial responsiveness to inhaled methacholine was measured by the astograph method. ${ }^{5}$ To evaluate response curves of total respiratory resistance (Rrs) three indices were defined as follows: (1) Rrs-cont: mean values of respiratory resistance during inhalation of saline; (2) Dmin: cumulative units of methacholine from the start of the study to the beginning of an increase in respiratory resistance; and (3) $\mathrm{PD}_{35}$-Grs: cumulative units of methacholine from the start of the study to the point at which total respiratory conductance decreased $35 \%$ from its baseline value. One unit represents one minute of inhalation of $1 \mathrm{mg} / \mathrm{ml}$ methacholine.

$\mathrm{FEV}_{1}$ and FVC were measured with a spirometer (OST-80A; CHEST, Tokyo) and the best of three satisfactory measurements was recorded. 
MEASUREMENT OF SERUM GOLD

CONCENTRATION

Five $\mathrm{ml}$ of blood was collected in a heparinised container before, and six and 12 weeks after, the start of treatment. Gold concentrations in the blood were measured by atomic absorption analysis spectrophotometry after the study had been completed.

\section{STATISTICAL ANALYSIS}

Twenty four patients, excluding one who was found to be suffering from a duodenal ulcer one week after the treatment, completed the study. Before unblinding the data all subjects were reviewed and five were excluded because of respiratory tract infection (two), a more than $25 \%$ change in Rrs-cont (two), and poor compliance (one).

Logarithmic transformation of Dmin and $\mathrm{PD}_{35}$-Grs was used for statistical analysis. Results were expressed as mean (SD). Results from the auranofin and placebo groups were compared by the unpaired Student's $t$ test and those within each group were compared by the paired Student's $t$ test.

\section{Results}

Efficacy data were analysed for the 19 subjects who completed the study. Nine patients received auranofin and 10 received an inactive placebo. Mean (SD) age in the auranofin group was $46 \cdot 2(12 \cdot 7)$ years and mean (SD) baseline $\mathrm{FEV}_{1}$ was $104.3 \%(20 \cdot 4 \%)$ of predicted. In the placebo group the mean age was $40.0(13.9)$ years and mean baseline $\mathrm{FEV}_{\text {, }}$ was $101.7 \%$ $(17.5 \%)$ of predicted. Eleven patients (five in the auranofin group and six in the placebo group) were receiving an inhaled steroid. Thus, there were no significant differences in age, baseline $\mathrm{FEV}_{1}$, or concomitant medications between the two groups.
As shown in the figure there was a significant improvement in Dmin $(p<0.05)$ and $\mathrm{PD}_{35}-\mathrm{Grs}(\mathrm{p}<0.05) 12$ weeks after auranofin treatment compared with 12 weeks after placebo treatment, although no significant differences in Dmin or $\mathrm{PD}_{35}-\mathrm{Grs}$ were found 0 and six weeks after treatments between the groups. In the auranofin group there was an improvement in Dmin $(\mathrm{p}<0.05)$ and $\mathrm{PD}_{35}-$ Grs $(p<0.05) 12$ weeks after the treatment compared with baseline. Treatment with auranofin for 12 weeks therefore significantly decreased non-specific bronchial responsiveness. In addition, after 12 weeks of treatment with auranofin the mean (SD) values of $\mathrm{PD}_{35}$-Grs increased from $0.652(0.474)$ to $0.921(0.668)$ units in five steroid-dependent asthmatic subjects and increased from $0.285(0.381)$ to 0.695 $(0.401)$ units in the remaining four patients. In contrast, the corresponding values in the placebo group were from $0.542(0.439)$ to 0.362 $(0.445)$ units in six steroid-dependent subjects and from $0.253(0.264)$ to $0.399(0.543)$ units in the remaining four subjects.

The mean (SD) values of baseline $\mathrm{FEV}_{1}$, FVC, and Rrs-cont are summarised in the table. There was a small decrease in $\mathrm{FEV}_{1}$ after treatment, and a statistically significant $(\mathrm{p}<0.05)$ decrease between 0 and 12 weeks. There was no significant difference in the placebo group. Thus, no improvement was seen in $\mathrm{FEV}_{1}, \mathrm{FVC}$, or Rrs-cont after either treatment.

The mean (SD) blood concentrations of gold were $0.003(0.001), 0.460(0.114)$, and $0.483(0.100) \mu \mathrm{g} / \mathrm{ml} 0$, six, and 12 weeks after the treatment, respectively. The concentrations after six and 12 weeks of treatment were therefore significantly higher than those after 0 weeks, although there was no significant difference in the concentration between six and 12 weeks. In the placebo group no increase in the blood concentration of gold was found in any of the subjects.
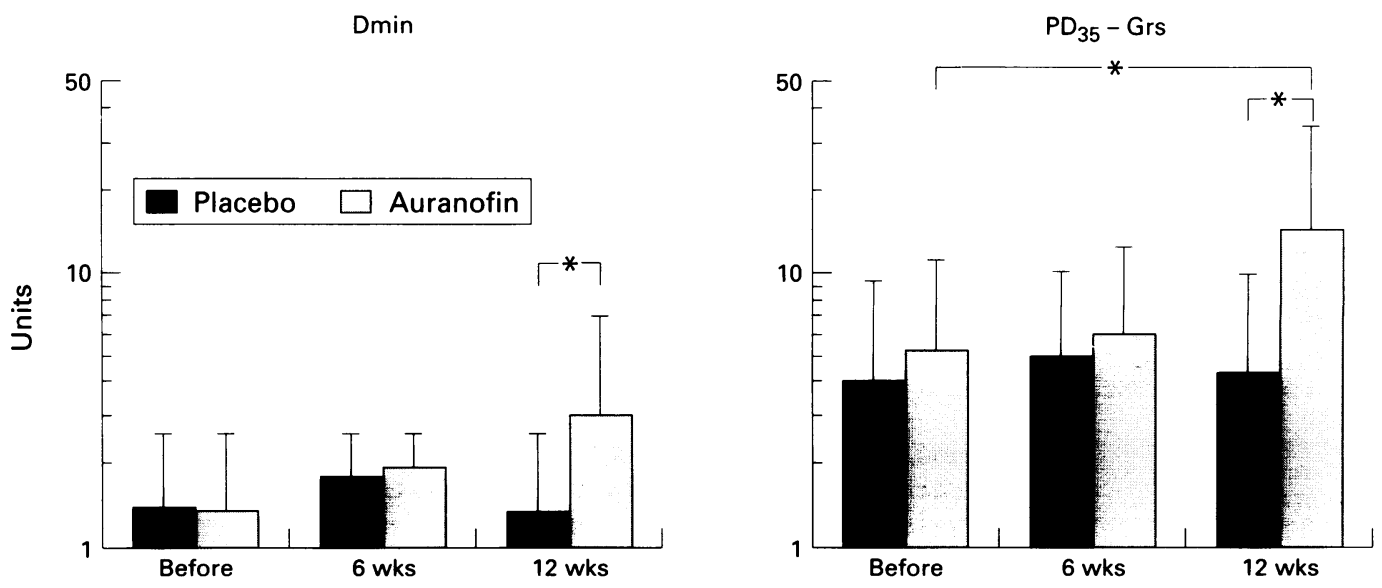

Changes in Dmin and $P D_{35}$-Grs 0, 6, and 12 weeks after treatment with auranofin or placebo. Compared with the placebo group patients in the auranofin group showed significant improvement in Dmin and PD ${ }_{35}-G r s$ after 12 weeks of treatment. Significant improvement in $P D_{35}-$ Grs occurred after 12 weeks of treatment with auranofin compared with the baseline value; ${ }^{*} p<0.05$. Dmin = cumulative units of methacholine from the start of the study to the beginning of an increase in total respiratory resistance; $P D_{35}-$ Grs $=$ cumulative units of methacholine from the start of the study to the point at which total respiratory conductance decreased $35 \%$ from its baseline values. 
Mean (SD) values of $F E V_{1}, F V C$, and $\% F E V$, to predicted values, and of respiratory resistance during inhalation of saline (Rrs-cont)

\begin{tabular}{|c|c|c|c|c|c|c|c|c|}
\hline & \multicolumn{4}{|c|}{ Placebo group } & \multicolumn{4}{|c|}{ Auranofin group } \\
\hline & $\begin{array}{l}F E V_{l} \\
(l)\end{array}$ & $\begin{array}{l}F E V_{1} \\
(\%)\end{array}$ & $\begin{array}{l}F V C \\
(l)\end{array}$ & $\begin{array}{l}\text { Rrs-cont } \\
\left(\mathrm{cm} \mathrm{H} \mathrm{H}_{2} \mathrm{O} / \mathrm{l} / \mathrm{s}\right)\end{array}$ & $\begin{array}{l}F E V_{l} \\
\text { (l) }\end{array}$ & $\begin{array}{l}F E V_{l} \\
(\%)\end{array}$ & $\begin{array}{l}F V C \\
(l)\end{array}$ & $\begin{array}{l}\text { Rrs-cont } \\
\left(\mathrm{cm} \mathrm{H} \mathrm{H}_{2} \mathrm{O} / \mathrm{l} / \mathrm{s}\right)\end{array}$ \\
\hline $\begin{array}{l}0 \text { weeks } \\
6 \text { weeks } \\
12 \text { weeks }\end{array}$ & $\begin{array}{l}2.84(0.81) \\
2.84(0.74) \\
2.78(0.73)\end{array}$ & $\begin{array}{r}101.7(17.5) \\
102.0(15 \cdot 2) \\
99.8(17.2)\end{array}$ & $\begin{array}{l}4.00(0.81) \\
3.96(0.82) \\
3.98(0.81)\end{array}$ & $\begin{array}{l}5 \cdot 3(1 \cdot 3) \\
5 \cdot 2(1 \cdot 2) \\
5 \cdot 3(1 \cdot 4)\end{array}$ & $\begin{array}{l}2.65(0.57) \\
2.56(0.73) \\
2.55(0.65)^{*}\end{array}$ & $\begin{array}{c}104 \cdot 3(20 \cdot 4) \\
99 \cdot 6(24 \cdot 2) \\
99 \cdot 6(22 \cdot 2)^{*}\end{array}$ & $\begin{array}{l}3.75(0.67) \\
3.64(0.95) \\
3.64(0.80)\end{array}$ & $\begin{array}{l}5.4(1.3) \\
5.4(1.6) \\
5.2(1.2)\end{array}$ \\
\hline
\end{tabular}

${ }^{*} \mathrm{p}<0.05$ compared with 0 weeks.

Four of the 11 patients treated with auranofin experienced gastrointestinal symptoms. Two patients suffered mild diarrhoea several days after starting auranofin, but the symptoms cleared within one week. The remaining two patients had loose stools throughout the study period but required no treatment. In one patient on placebo, diarrhoea was also observed. None of the patients exhibited any biochemical or haematological changes at 12 weeks after either treatment.

\section{Discussion}

Bronchial hyperresponsiveness has been reported to be increased by various stimuli and also by exacerbations of asthma. ${ }^{67}$ On the other hand, long term treatment with gold compounds decreased hyperresponsiveness in an open trial. ${ }^{1}$ To avoid other factors which might influence the responsiveness only asymptomatic asthmatic subjects were selected for the present study. Some of the subjects were therefore taking inhaled steroids which may have improved their bronchial hyperresponsiveness and baseline pulmonary function tests. ${ }^{89}$ The 12 weeks of treatment with auranofin significantly improved non-specific bronchial hyperresponsiveness without any bronchodilator effect, suggesting that bronchial hyperresponsiveness after treatment with auranofin was significantly decreased in a group of mild asymptomatic asthmatic patients with normal lung function.

Bronchial hyperresponsiveness has been reported to be increased by various substances such as antigen, ${ }^{10}$ sulphur dioxide, ${ }^{11}$ ozone, ${ }^{12}$ leukotriene $\mathrm{E}_{4},{ }^{13}$ platelet activating factor, ${ }^{14}$ toluene diisocyanate, ${ }^{15}$ and $\mathrm{C} 5 \mathrm{a} .{ }^{16}$ Auranofin has been reported to inhibit the release of histamine ${ }^{17}$ and leukotriene $\mathrm{C}_{4}{ }^{18}$ from human basophils and mast cells stimulated by IgE, to inhibit release of leukotriene $C_{4}$ and $B_{4}$ from human peripheral leucocytes stimulated by fMLP, ${ }^{19}$ to inhibit generation of superoxide radicals from human peripheral leucocytes, ${ }^{20}$ and to inhibit the chemotactic activity of human mononuclear leucocytes. ${ }^{21}$ The antiallergic effects of auranofin may therefore be responsible for the decrease in bronchial hyperresponsiveness, although the precise mechanism of its action requires further investigation.

Serious adverse effects have been reported following parenteral therapy with gold compounds. However, in this study only gastro- intestinal symptoms were observed and no treatment was required. Thus, no serious adverse effects were found, as is consistent with previous reports on the action of auranofin.

1 Muranaka M, Nakajima K, Suzuki S. Bronchial responsiveness to acetylcholine in patients with bronchial asthma after long-term treatment with gold salt. $\mathcal{F}$ Allergy Clin Immunol 1981; 67:350-6.

2 Sutton BM, McGusty E, Walz DT, DiMartino MJ. Oral gold. Antiarthritic properties of alkylphosphinegold coordination complexes. $\mathcal{F}$ Med Chem 1972;15:1095-8.

3 Smith PR, Brown GMM, Meyers OL. An open comparative study of auranofin $v$ gold sodium thiomalate. $\mathcal{F}$ Rheumatol 1982;9(Suppl 8):190-6.

4 Bernstein DI, Bernstein IL, Bodenheimer SS, Pietrusko RG. An open study of auranofin in the treatment of steroid-dependent asthma. $\mathcal{f}$ Allergy Clin Immunol 1988;81:6-16

5 Takishima T, Hida W, Sasaki H, Suzuki S, Sasaki T. Direct-writing recorder of the dose-response curves of the airway to methacholine. Chest 1981;80:600-6.

6 Brooks SM, Leonard Bernstein I, Raghuprasad PK, Maccia CA, Mieczkowski L. Assessment of airway hyperresponsiveness in chronic stable asthma. 7 Allergy Clin Immuno 1990;85:17-26.

7 Ryan G, Latimer KM, Dolovich J, Hargreave FE. Bronchial responsiveness to histamine: relationship to diurnal variation of peak flow rate, improvement after bronchodivariation of peak flow rate, improvement after bronc

8 Ryan G, Latimer KM, Juniper EF, Roberts RS, Tech M, Hargreave FE. Effect of beclomethasone dipropionate on bronchial responsiveness to histamine in controlled nonsteroid-dependent asthma. $\mathcal{f}$ Allergy Clin Immuno 1985;75:25-30.

9 Kraan J, Koëter GH, Van Der Mark THW, Boorsma M Kukler J, Sluiter HJ, et al. Dosage and time effects of inhaled budesonide on bronchial hyperreactivity. Am Rev Respir Dis 1988;137:44-8.

10 Cockroft DW, Ruffin RE, Dolovich J, Hargreave FE. Allergen-induced increase in non-allergic bronchial reactivity. Clin Allergy 1977;7:503-13.

11 Katsumata U, Miura M, Ichinose M, Kimura K, Takahashi $\mathrm{T}$, Inoue $\mathrm{H}$, et al. Oxygen radicals produce airway con$\mathrm{T}$, Inoue $\mathrm{H}$, et al. Oxygen radicals produce airway constriction and hyperresponsiveness in

12 Golden JA, Nadel JA, Boushey HA. Bronchial hyperirritability in healthy subjects after exposure to ozone. Am Rev Respir Dis 1978;118:287-94.

13 Arm JP, Spur BW, Lee TH. The effects of inhaled leukotriene $\mathrm{E}_{4}$ on the airway responsiveness to histamine in subjects with asthma and normal subjects. $\mathcal{f}$ Allergy Clin Immunol 1988;82:654-60.

14 Cuss FM, Dixon CMS, Barnes PJ. Effects of inhaled platelet activating factor on pulmonary function and
bronchial responsiveness in man. Lancet 1986;ii:189-92.

15 Gordon T, Sheppard D, McDonald DM, Distefano S, Scypinski L. Airway hyperresponsiveness and inflammaScypinski $\mathrm{L}$. Airway hyperresponsiveness and inflamma-
tion induced by toluene diisocyanate in guinea pigs. $\mathrm{Am}$ tion induced by toluene diisocyan
Rev Respir Dis 1985;132:1106-12.

16 Irvin CG, Berend N, Henson PM. Airway hyperreactivity and inflammation produced by aerosolization of human C5A des arg. Am Rev Respir Dis 1986;134:777-83.

17 Takaishi T, Morita Y, Kudo K, Miyamoto T. Auranofin, an oral chrysotherapeutic agent, inhibits histamine release from human basophils. $\mathcal{f}$ Allergy Clin Immunol 1984;74:297-301.

18 Marone G, Columbo M, Galeone D, Guidi G, KageySobotka A, Lichtenstein LM. Modulation of the release of histamine and arachidonic acid metabolites from human basophils and mast cells by auranofin. Agents Actions man basophils a

19 Parente JE, Wong K, Davis P, Burka JF, Percy JS. Effects of gold compounds on leukotriene $B_{4}$, leukotriene $C_{4}$ and prostaglandin $\mathrm{E}_{2}$ production by polymorphonuclear leukocytes. $f$ Rheumatol 1986;13:47-51

20 Walz DT, DiMartino MJ, Griswold DE, Intoccia AP Flanagan TL. Biologic actions and pharmacokinetic studies of auranofin. Am $\mathcal{F}$ Med 1983;75(Suppl):90-108.

21 Scheinberg MA, Santos LMB, Finkelstein AE. The effect of auranofin and sodium aurothiomalate on peripheral blood monocytes. F Rheumatol 1982;9:366-9. 